Sains Malaysiana 50(6)(2021): 1599-1608

http://doi.org/10.17576/jsm-2021-5006-08

\title{
Komunikasi Pendek: Penanaman Cendawan Jerami Volvariella volvacea menggunakan Sisa Biojisim Pisang
}

(Short Communication: Cultivation of Straw Mushroom Volvariella volvacea using Banana Biomass Waste)

\author{
Hanisom Abdullah*, Norlida Othman, Marina Mokhtar, Mohamad Yuzaidi Azmi, Azhar Mohamad \& \\ NORJAN YUSOF
}

\begin{abstract}
ABSTRAK
Di Malaysia, penanaman cendawan Volvariella volvacea secara komersial telah bermula pada tahun 2014. Pada peringkat awal, jerami padi telah digunakan sebagai media pertumbuhan. Walau bagaimanapun, penggunaan jerami padi telah didapati mempunyai beberapa kelemahan seperti kurang kebolehdapatan di seluruh negara, bermusim, hasil kutipan rendah dan penyediaan media yang rumit kerana memerlukan proses pemotongan dan perendaman dalam air kapur. Dalam tahun kebelakangan ini, tandan buah kosong kelapa sawit (TBK) didapati mampu memberikan hasil kutipan yang lebih tinggi berbanding jerami padi. Proses penyediaan media TBK juga lebih ringkas, tidak memerlukan pemotongan ke saiz kecil. Kos penyediaan media TBK adalah rendah secara relatif memandangkan TBK banyak diperoleh sebagai sisa kilang minyak sawit sepanjang tahun. Selain jerami padi dan TBK, penggunaan biojisim lain seperti daun pisang kering yang terbukti berjaya di negara Filipina dan Ghana, belum pernah dilaporkan dalam domain umum di Malaysia. Kajian ini dijalankan untuk menguji kebolehlaksanaan penanaman V. volvacea menggunakan sisa biojisim pisang. Kebolehmandirian V. volvacea dikaji menggunakan kaedah batas dan bakul di lapangan. Hasil kajian mendapati bahawa kaedah batas memberikan hasil kutipan cendawan yang lebih tinggi berbanding kaedah bakul. Secara purata, $2.5 \mathrm{~kg}$ cendawan segar berjaya diperoleh daripada setiap batas tanaman. Oleh kerana setiap batas dibina daripada $24 \mathrm{~kg}$ daun pisang kering, Koefisien Pertukaran Biologi (KPB) bagi kaedah ini adalah 10.4\% manakala KBP bagi kaedah bakul adalah lebih rendah secara ketara pada 8.3\% (1.0 kg cendawan segar/12 kg media). Walaupun banyak pemboleh ubah kajian memerlukan pengoptimuman pada masa akan datang, kajian ini berjaya memperoleh data asas untuk dijadikan kerangka rujukan bagi penanaman cendawan V. volvacea secara integrasi dengan tanaman pisang. Menggunakan konsep permakultur, sisa biojisim daripada ladang pisang boleh digunakan secara mampan bagi penanaman cendawan $\mathrm{V}$. volvacea untuk menjana pendapatan baharu.
\end{abstract}

Kata kunci: Biojisim; cendawan jerami; pisang; sisa; Volvariella volvacea

\section{ABSTRACT}

In Malaysia, commercial cultivation of Volvariella volvacea mushroom started in the year of 2014. At the beginning, rice straw biomass was used as a growth media. However, the application of rice straw biomass has several disadvantages such as low availability throughout the country, seasonal, low yield, and complex media preparation since it requires cutting and soaking in lime solution. In recent years, oil palm empty fruit bunch (EFB) was found to give higher mushroom yield than that of a rice straw. The process of media preparation using EFB is simpler without the need of any size modification. EFB is also abundant as waste from palm oil mills, and it could be obtained at relatively low cost all year round. Besides rice straw and EFB, application of other biomass such as dry banana leaf, which was proven to be successful in the Philippines and Ghana, but has yet been reported in Malaysia's public domains. This study was conducted to evaluate the feasibility of $\mathrm{V}$. volvacea mushroom cultivation using banana biomass waste. The survival of the V. volvacea mushrooms was studied by cultivation using bed and basket methods in the field. The results showed that the bed planting method yielded higher fresh mushrooms than the basket method. An average of $2.5 \mathrm{~kg}$ fresh mushrooms was obtained from each media bed. Each media bed was built with $24 \mathrm{~kg}$ of dried banana leaf, therefore, the Biological Conversion Efficiency (BCE) of this method was 10.4\%. For basket method, the BCE was significantly lower at $8.3 \%$ (1.0 kg fresh mushroom $/ 12 \mathrm{~kg}$ media). Although many of the study parameters could be optimized in the future, this study has successfully garnered baseline data as reference framework for the integrative cultivation of $\mathrm{V}$. volvacea mushrooms with banana crop. Using the permaculture concept, biomass waste from banana plantation can be sustainably applied to plant $\mathrm{V}$. volvacea mushrooms for new income generation.

Keywords: Biomass; banana; straw mushroom; Volvariella volvacea; waste 


\section{PENGENALAN}

Cendawan ialah salah satu komoditi agro-makanan yang telah dikenal pasti dapat memacu pertumbuhan ekonomi baharu dalam industri pertanian di Malaysia (Kementerian Pertanian dan Industri Asas Tani Malaysia 2011). Dianggarkan 1,000 tan cendawan dihasilkan secara komersial setiap tahun untuk pasaran tempatan dan eksport merangkumi lapan jenis cendawan, iaitu abalone (Pleurotus cystidiosus), jerami (Volvariella volvacea), telinga kera (Auricularia polytricha), tiram kelabu (Pleurotus sajor-caju), tiram putih (Pleurotus florida), tiram merah (Pleurotus flabellatus), ganoderma (Ganoderma applanatum) dan shiitake (Lantinus sp.) (Amin et al. 2014). Industri cendawan di Malaysia menunjukkan peningkatan nilai eksport daripada RM12 juta pada tahun 2000 kepada RM67 juta pada tahun 2010. Sebanyak 49\% daripada keluaran cendawan ini dieksport segar terutama ke Singapura dan selebihnya dalam bentuk proses (Kementerian Pertanian dan Industri Asas Tani Malaysia 2011). Malaysia merupakan negara ke-sepuluh pengeksport cendawan kering dunia dengan jumlah eksport melebihi 1,000 tan pada tahun 2012 (Comtrade 2012).

Cendawan disasarkan sebagai makanan berfungsi yang mempunyai prospek luas dalam industri nutraseutikal, farmaseutikal dan kosmeseutikal. Antara cendawan yang dikenali mempunyai nilai perubatan adalah ganoderma (Ganoderma sp.), shiitake (Lantinus sp.) dan cendawan jerami (Volvariella volvacea) (Marshall \& Nair 2009). Walau bagaimanapun, ketiga-tiga jenis cendawan ini belum ditanam secara meluas di Malaysia. Pada tahun 2015, pengeluaran cendawan negara lebih tertumpu kepada cendawan tiram kelabu (Pleurotus pulmonarius), iaitu sebanyak $90.89 \%$ berbanding ganoderma (1.64\%), shiitake $(0.70 \%)$ dan cendawan jerami (0.47\%) (Amin et al. 2014). Terdapat beberapa isu dan cabaran utama yang perlu diberi perhatian dalam industri cendawan negara.

Antara isu utama adalah wujud ketidakseimbangan antara permintaan dan bekalan cendawan. Sejajar dengan peningkatan populasi penduduk dan kesedaran penjagaan kesihatan, permintaan pengguna terhadap cendawan juga semakin meningkat. Purata pengambilan cendawan dianggarkan meningkat secara relatif daripada $1.0 \mathrm{~kg} /$ orang pada tahun $2008 \mathrm{kepada} 2.4 \mathrm{~kg} /$ orang pada tahun 2020 (Kementerian Pertanian dan Industri Asas Tani Malaysia 2011). Namun dari segi bekalan, hanya sebahagian kecil penanaman cendawan dilakukan oleh syarikat besar dengan kapasiti pengeluaran cendawan segar melebihi $500 \mathrm{~kg} /$ hari. Sebanyak $80 \%$ penanam cendawan adalah pekebun kecil yang menghasilkan kurang daripada $50 \mathrm{~kg} /$ hektar cendawan segar setiap hari
(Haimid et al. 2013) dan ini menyebabkan berlakunya masalah ketidakstabilan pengeluaran. Antara cabaran yang dihadapi oleh penanam kecil cendawan adalah kurang kemudahan untuk menghasilkan kompos berkualiti dan benih cendawan, kekurangan sumber kewangan untuk meningkatkan kemudahan, kaedah pengeluaran dan meneroka pasaran baharu serta kurang ilmu tentang teknologi penghasilan terkini dan amalan pengurusan ladang (Rosmiza et al. 2016). Teknologi pengeluaran cendawan di Malaysia tidak mengalami banyak perubahan sejak ia diperkenalkan pada tahun 1960-an. Majoriti pekebun komersial menggunakan media substrat habuk kayu getah terutama untuk penanaman cendawan tiram (Rosmiza et al. 2016). Walaupun Malaysia kaya dengan biojisim pertanian lain seperti sisa kelapa sawit, koko, padi dan pisang, sumber-sumber ini belum digunakan secara optimum dalam penanaman cendawan dan memerlukan kajian terperinci. Antara cendawan yang boleh tumbuh dalam banyak jenis biojisim adalah cendawan jerami Volvariella volvacea (Ahlawat \& Tewari 2007; Della 2017). Volvariella volvacea adalah salah satu cendawan yang sesuai dijadikan sebagai makanan berfungsi kerana mempunyai sifat anti tumor, anti radang, rendah kalori dan kaya dengan karbohidrat, serat dan protein. Ia juga kaya dengan asid amino perlu seperti asid glutamik dan valina, mineral kalium, tiamina, fosforus dan vitamin seperti vitamin C dan B3 (Ahlawat \& Tewari 2007; Eguchi et al. 2015; Roy et al. 2014). V. volvacea mampu tumbuh dalam berbagai media biojisim sama ada terkompos atau tidak seperti jerami padi, sisa kapas, bahan buangan organik selulosa, sisa kelapa sawit dan sisa teh (Ahlawat \& Tewari 2007; Della 2017).

Kitaran penanaman $V$. volvacea lengkap mengambil masa antara 4 dan 5 minggu. Di Malaysia, sejarah penanaman cendawan jerami bermula dari tahun 1960an dan dijalankan pada skala kecil. Sehingga pada tahun 2014, penanaman cendawan jerami secara komersial mula diperkenalkan kembali oleh Jabatan Pertanian Daerah Padang Terap, Kedah. Pada peringkat awal percubaan, media tanaman yang digunakan adalah jerami padi. Di negara jiran seperti Vietnam, media jerami padi banyak digunakan sebagai media di batas terbuka atas tanah dan bangsal/rumah cendawan kerana kebolehdapatan jerami padi yang tinggi (Le Vinh et al. 2019). Walau bagaimanapun, di Malaysia terdapat beberapa kelemahan dengan media ini seperti kurang kebolehdapatan kerana jerami padi hanya diperoleh semasa musim penanaman padi. Fasa penyediaan media juga agak renyah kerana memerlukan jerami dipotong pendek dan direndam dalam air kapur terlebih dahulu (Della 2017; Le Vinh et al. 2019) untuk mengelakkan serangan kulat dan kulapuk yang 
mengganggu pertumbuhan $V$. volvacea. Melalui beberapa percubaan, didapati hasil yang baik berjaya diperoleh menggunakan tandan sawit yang telah dikomposkan (Sakinah et al. 2019). Kaedah ini diadaptasi daripada teknologi yang diguna pakai di Thailand dan Indonesia (Sugalya et al. 2015; Triyono et al. 2019).

Pada peringkat awal, penanaman cendawan jerami di Daerah Padang Terap adalah disasarkan sebagai alternatif kepada pekebun getah yang terjejas pendapatan akibat fenomena cuaca panas melampau dan kejatuhan harga getah (Sakinah et al. 2019). Inovasi teknologi berkonsepkan 3T (Tanam, Tunggu dan Tuai) ini telah berjaya memenangi tempat pertama bagi kategori awam dan Johan Keseluruhan dalam Konvensyen Pertandingan Inovasi Inklusif 2015. Seterusnya, teknologi penanaman cendawan jerami ditambah baik dengan kerjasama Agensi Nuklear Malaysia di bawah Program MOSTI Social Innovation (MSI) 2016 'Mushroom for Community'.

Agensi Nuklear Malaysia telah berjaya membangunkan benih cendawan jerami bermutu tinggi yang tahan cuaca dan pendek masa pengeluaran melalui teknik mutagenesis sinaran gamma (Yusof et al. 2019). Di bawah program MSI ini, sebuah makmal pengeluaran benih cendawan juga telah dibina di Padang Nyior, Daerah Padang Terap untuk dimanfaatkan oleh komuniti (Yusof et al. 2019). Kaedah penanaman cendawan jerami menggunakan batas tandan sawit didapati amat sesuai untuk dilaksanakan di ladang getah dan kawasan pertanian yang redup di daerah ini. Antara kelebihan penanaman cendawan jerami menggunakan kaedah ini ialah pengurusan yang mudah, berkos rendah dengan modal permulaan serendah RM1000.00 untuk 20 batas berukuran $15 \times 3$ kaki persegi, tidak memerlukan pembinaan rumah cendawan khas dan memaksimumkan penggunaan tanah dalam kebun getah (Sakinah et al. 2019). Kini, teknologi penanaman cendawan jerami menggunakan tandan sawit mula diperluaskan ke seluruh negeri melalui kerjasama agensi seperti jabatan pertanian, RISDA dan FELDA.

Selain daripada biojisim tandan sawit dan jerami padi, tidak banyak penggunaan biojisim lain dilaporkan sebagai media tanaman $V$. volvacea di Malaysia. Kajian kepustakaan mendapati media daun pisang kering telah disarankan oleh Jabatan Pertanian Filipina (2018) sebagai media yang sesuai untuk penanaman cendawan jerami secara kaedah terbuka di ladang-ladang di Filipina. Di Filipina, contoh hasil yang berjaya diperoleh untuk plot bersaiz $15 \mathrm{~m}(\sim 49$ kaki) $\times 1$ kaki lebar dan 1 kaki tinggi ialah $\sim 33 \mathrm{~kg}$ selama tempoh pusingan sebulan (Maning Garden-Philippines 2009). Dengan menggunakan media daun pisang kering yang tidak perlu dikomposkan berbanding tandan kelapa sawit, dianggarkan tempoh pusingan penanaman dapat dipendekkan sehingga separuh.

Kesesuaian media daun pisang kering dalam penanaman cendawan turut disokong oleh kajian lepas. Pelbagai media telah diuji dalam penanaman cendawan jerami di Ghana, hasil kajian telah menunjukkan peningkatan Keefisienan Pertukaran Biologi (KPB; nisbah berat cendawan per berat kering substrat) ketara bagi substrat daun pisang tanduk kering iaitu $25 \%$ berbanding hanya $1.6 \%$ bagi tandan sawit. Campuran daun pisang kering dan tandan sawit pula menunjukkan KPB sebanyak 11.2\% sahaja (Apetorgbor et al. 2015). Hasil kajian ini menunjukkan daun pisang kering tanpa campuran adalah jauh lebih sesuai sebagai media penanaman cendawan berbanding dengan tandan sawit.

Selain itu, penggunaan semula sisa biojisim pisang untuk penanaman tanaman lain dapat memperbaiki amalan ladang pisang konvensional supaya lebih mesra alam. Tinjauan amalan pertanian konvensional ladang pisang komersial mendapati lazimnya, pokok pisang ditanam dalam senggang jarak secara barisan untuk memudahkan pengurusan ladang. Daun pisang yang kering dicantas dan dibersihkan meninggalkan helaian daun dalam setiap pokok pisang sebanyak 8 helai sahaja. Dalam kebanyakan ladang pisang konvensional, hanya produk tunggal komoditi pisang yang dihasilkan tanpa ada integrasi dengan tanaman yang lain. Sisa pertanian utama dalam ladang pisang konvensional adalah daun pisang kering, tandan setelah sikat buah pisang dipetik dan batang pokok yang ditebang selepas pengambilan buah. Sekiranya sisa ladang pisang ini dapat dimanfaatkan untuk penghasilan produk bernilai tinggi dengan kos rendah seperti cendawan $V$. volvacea melalui konsep 'Sisa Buangan Menjadi Kekayaan', petani akan dapat menjana sumber ekonomi baharu dengan mengoptimumkan keluasan ladang di samping komoditi pisang sedia ada.

Objektif utama kajian ini adalah untuk menilai kebolehlaksanaan penanaman cendawan $V$. volvacea menggunakan sisa biojisim pisang sebagai media. Penggunaan sisa biojisim pisang telah dikaji sebagai media pertumbuhan cendawan $V$. volvacea semasa fasa pembuatan bongkah dan fasa pertumbuhan untuk pembentukan jasad cendawan. Data penemuan awal kajian ini memberikan manfaat kepada pihak berkepentingan dalam industri cendawan negara dan komuniti saintifik. Isu dan cabaran utama yang dihadapi juga turut dilaporkan. Hasil kajian ini boleh menjadi rujukan asas terutama bagi pengoptimuman pemboleh ubah berkaitan untuk kajian masa hadapan. 


\section{BAHAN DAN KAEDAH PENYELIDIKAN}

\section{PENGKULTURAN $V$. volvacea}

Stok kultur $V$. volvacea diperoleh daripada Makmal Pusat Pengeluaran dan Pembangunan Cendawan, Padang Nyior, Daerah Padang Terap, Kedah. Stok kultur $V$. volvacea ini dibangunkan oleh Agensi Nuklear Malaysia melalui teknik mutagenesis sinaran gamma pada tahun 2016. Kesemua proses pengkulturan dan pensubkulturan dalam kajian ini dilakukan dalam kabinet aliran laminar menggunakan teknik aseptik. Kultur stok $V$. volvacea dikekalkan dalam media pertumbuhan agar ubi kentang-dekstrosa yang telah disteril untuk memastikan kemandirian miselium cendawan. Bagi penghasilan bongkah cendawan, miselium cendawan perlu disubkultur dahulu daripada media agar ubi kentang-dekstrosa ke dalam media pertumbuhan bijirin. Untuk menghasilkan media pertumbuhan bijirin, sebanyak $1.0 \mathrm{~kg}$ biji jagung (gred pertanian) dan $10.0 \mathrm{~g}$ kapur (gred pertanian) telah digunakan. Biji jagung yang telah dibersihkan direndam dalam air suling selama $30 \mathrm{~min}$. Kemudian biji jagung disejat dan dibiarkan selama 12 jam pada suhu bilik untuk menjadikan kelembapannya 60\% sebelum digaulkan dengan kapur pertanian. Seterusnya, sebanyak $70.0 \mathrm{~g}$ biji jagung bercampur kapur diisikan ke dalam beg plastik lutsinar jenis polipropilena, ditutup dengan penutup bongkah dan disteril menggunakan autoklaf $\left(121{ }^{\circ} \mathrm{C}, 10\right.$ min). Beg bijirin tersteril kemudian disejukkan pada suhu bilik. Bagi proses pensubkulturan miselium, sebanyak 3 keping potongan agar ubi kentang-dekstrosa bersaiz 1 $\mathrm{cm}^{2} /$ keping yang telah ditumbuhi miselium dikultur ke dalam beg bijirin. Beg bijirin kemudian ditutup rapat dan disimpan pada suhu bilik sehingga percambahan miselium diperhatikan dalam jangka masa 12-14 hari.

\section{PEMBUATAN BONGKAH}

Bagi pembuatan bongkah cendawan, campuran media serabut kekabu, serat batang pisang kering dan kapur pertanian digunakan. Kesemua bahan yang digunakan dalam penghasilan beg media bijirin dibeli dan penghasilan bongkah dibeli daripada pembekal bahan pertanian tempatan. Serat batang pisang kering diperoleh daripada serabut luar batang pokok pisang yang telah tua, menipis dan berwarna coklat. Tiada pengeringan lanjutan dilakukan. Sebanyak $6.0 \mathrm{~kg}$ serat daripada batang pisang kering diracik dengan mesin peracik sehingga bersaiz anggaran $5 \mathrm{~cm}$ panjang. Selepas itu, serat batang pisang direndam selama 6 jam dalam air suling, ditapis dan dibiarkan di tempat yang teduh selama 12 jam untuk mencapai anggaran kelembapan $60 \%$ sebelum digaul dengan serat kekabu dan kapur pertanian dalam nisbah 1: 0.5 , iaitu $1.0 \mathrm{~kg}$ serat kekabu dengan $500.0 \mathrm{~g}$ kapur pertanian.

Bagi isian beg bongkah, sebanyak $70.0 \mathrm{~g}$ daripada campuran substrat serat batang pisang, kekabu dan kapur dimasukkan ke dalam setiap beg plastik lutsinar polipropilena, ditutup dengan penutup tudung bongkah dan disterilkan menggunakan autoklaf $\left(121^{\circ} \mathrm{C}, 30 \mathrm{~min}\right)$. Beg substrat tersteril kemudian disejukkan pada suhu bilik sebelum diinokulasi dengan miselium cendawan daripada media bijirin. Sebelum proses pensubkulturan miselium dilakukan, bahagian bukaan beg bongkah disembur dengan larutan detergen (Dettol 5\%) kemudian dibiarkan selama 5 min sebelum dilap kering. Sebanyak 2.0 g media bijirin bermiselium dimasukkan ke dalam beg bongkah dan ditutup dengan penutup. Beg bongkah dibiarkan pada suhu bilik untuk membenarkan pertumbuhan miselium dalam jangka masa 14-17 hari.

\section{PENGHASILAN JASAD CENDAWAN}

Selain daripada bongkah cendawan yang telah disediakan sebelumnya, bahan lain dan alat untuk penanaman cendawan adalah daun pisang kering, daun kacang moringa (Moringa oleifera), baja organik, plastik polipropilena hitam dan kayu pancang sebagai penyangga yang diperoleh daripada pembekal pertanian. Daun pisang kering digunakan bersekali dengan pelepah daun pisang yang tua tanpa pengeringan lanjutan. Dalam kajian ini, tidak ada pengkhususan spesies pisang yang digunakan untuk menghasilkan sisa biojisim yang diperlukan bagi pembuatan bongkah dan penanaman cendawan. Penyediaan media penanaman daun pisang kering adalah mudah, iaitu daun pisang kering yang masih terlekat pada pelepah daun direndam ke dalam air paip bersih selama 2 jam dalam tangki rendaman. Kemudian ia ditoskan sehingga tiada air menitik sebelum dipotong melintang sepanjang 1 kaki. Penanaman cendawan $V$. volvacea secara organik telah dikaji menggunakan dua kaedah, iaitu kaedah batas dan kaedah bakul. Lokasi plot tanaman adalah sebuah kawasan dusun di Felda Sg. Behrang, Perak. Uji kaji di lapangan ini berjalan sepanjang bulan April sehingga Ogos 2018 dan ia tidak melibatkan sebarang kawalan keadaan di plot tanaman.

Bagi kaedah batas, terlebih dahulu kawasan yang redup di bawah kanopi pokok dipilih dan dibersihkan daripada rumput rampai. Untuk batas tanaman berdimensi 
$5 \times 1 \times 1$ kaki padu, sebanyak $24 \mathrm{~kg}$ daun pisang kering diperlukan. Bagi membuat batas tanaman, potongan daun pisang yang bersaiz 1 kaki yang telah direndam disusun menegak di atas tanah membentuk 1 lapisan. Kemudian 1 sudu besar baja organik ( $20 \mathrm{~g})$ diletak berjarak 2 inci dari birai daun pisang dan ditompokkan bersela jarak 4 inci sehingga ke hujung batas. Peletakan baja organik ini diulang pada kedua-dua belah batas. Di tengah-tengah antara sela baja organik pula diletakkan 1 sudu besar media bongkah $(5.0 \mathrm{~g})$ yang telah ditumbuhi miselium cendawan. Kemudian, daun kacang moringa diletakkan memanjang sepanjang batas menutupi baja dan benih cendawan. Daun kacang moringa digunakan sebagai bahan pembekal nitrogen organik untuk pertumbuhan cendawan. Kemudian, selapisan lagi daun pisang diatur menutupi batas dan ditekan supaya mampat. Langkah peletakan baja organik, benih cendawan, daun kacang moringa dan daun pisang seperti diterangkan diulang sebanyak 4 kali untuk mendapat 5 lapisan keseluruhannya. Adalah penting batas ditekan untuk dimampatkan pada setiap lapisan. Setelah selesai, kayu pancang dipasang di hujung batas. Kemudian, plastik polipropilena hitam dipasang menutupi batas dan disangga dengan kayu pancang supaya lapisan plastik tidak mengenai batas media.

Untuk kaedah bakul, anggaran seberat $1.5 \mathrm{~kg}$ daun pisang kering diperlukan bagi setiap bakul plastik bersaiz $34 \mathrm{~cm}$ (diameter dalam) $\times 34 \mathrm{~cm}$ tinggi. Proses yang hampir sama dengan kaedah batas dilakukan, iaitu daun pisang kering, baja organik, benih cendawan dan daun moringa disusun berlapis di dalam bakul sehingga 5 lapisan. Bagi setiap lapisan, anggaran $300.0 \mathrm{~g}$ daun pisang kering, $25.0 \mathrm{~g}$ benih cendawan dan $100.0 \mathrm{~g}$ baja organik diperlukan. Lapisan media kemudian ditekan hingga mampat. Sebanyak 8 buah bakul media disediakan melalui kaedah ini. Kemudian semua bakul disusun di atas tanah dan ditutup dengan plastik polipropilena hitam. Bagi kedua-dua kaedah batas dan bakul, suhu dan kelembapan udara direkodkan setiap hari pada jam 9.00 pagi dan 3.00 petang untuk mengukur naik turun dua faktor ini sepanjang uji kaji berjalan.

\section{HASIL DAN PERBINCANGAN}

Lazimnya, bagi penanaman $V$. volvacea di batas media tandan sawit, pembuatan bongkah cendawan melibatkan pengkulturan miselium dalam media serabut jerami padi dan kekabu. Dalam kajian ini, pembuatan bongkah cendawan telah dicuba menggunakan campuran media serabut kekabu dan serat batang pisang kering untuk mengkondisikan pertumbuhan miselium bagi meningkatkan kemandiriannya di batas media daun pisang kering. Hasil kajian mendapati miselium $V$. volvacea boleh tumbuh dengan baik dalam campuran media serabut kekabu dan serat batang pisang. Pertumbuhan siratan hifa berupa kapas di media bongkah mulai kelihatan selepas 14 hari dari hari pertama pengkulturan.

Bagi uji kaji pertumbuhan jasad cendawan, didapati kaedah batas memberikan hasil yang lebih baik daripada kaedah bakul. Batas media dibiarkan selama 14 hari tanpa dibuka penutup plastik sebelum hasil cendawan dapat dituai. Peringkat perkembangan cendawan jerami telah diperhatikan di batas media (Rajah 1). Pertumbuhan jasad cendawan mula kelihatan pada hari ke-12 dengan fasa mata pin dan butang kecil terbentuk daripada jalinan hifa yang bercantum (Rajah 1(a)). Seterusnya, pada hari ke-14 sehingga hari ke-15, fasa mata pin dan butang kecil berkembang menjadi fasa butang dan jasad telur pula (Rajah 1(b)). Pada hari ke-16 (Rajah 1(c)), jasad telur berkembang ke peringkat akhir jasad telur sebelum menjadi cendawan matang pada hari ke-17 atau 18 (Rajah 1(d)). Sepanjang tempoh hari ke-15 hingga 18, kutipan jasad cendawan dibuat. Selepas kutipan pertama ini, batas ditutup kembali untuk inkubasi dan pemantauan perkembangan cendawan dibuat setiap hari untuk 3 hingga 5 hari berikutnya.

Untuk setiap batas bersaiz $5 \times 1 \times 1$ kaki padu, purata hasil cendawan segar yang berjaya diperoleh adalah 2.5 $\mathrm{kg}$ (triplikasi, ralat piawai purata $<1 \%$ ). Sementara itu, dalam kaedah bakul sebanyak $1.0 \mathrm{~kg}$ cendawan segar dituai daripada 8 buah bakul (triplikasi, ralat piawai purata $<1 \%$ ). Sebanyak $20 \%$ hasil kutipan diperoleh pada hari ke-15 manakala majoriti hasil kutipan $(80 \%)$ diperoleh semasa kutipan pada hari ke-16 hingga 18. Peratus PKB yang mengukur kecekapan pertukaran substrat kering ke jisim cendawan segar adalah $10.4 \%$ (2.5 kg cendawan segar untuk $24 \mathrm{~kg}$ media, ralat piawai purata daripada triplikasi 1.6\%) bagi kaedah batas dan $8.3 \%(1.0 \mathrm{~kg}$ cendawan segar bagi $12 \mathrm{~kg}$ media, ralat piawai purata daripada triplikasi $1.5 \%$ ) bagi kaedah bakul. Nilai PKB yang diperoleh daripada kajian ini adalah lebih rendah berbanding kajian lepas.

Apetorgbor et al. (2015) melaporkan nilai PKB substrat daun pisang tanduk kering bagi penanaman $V$. volvacea sebanyak $25 \%$, dan mereka juga memperoleh nilai PKB bagi campuran daun pisang tanduk kering dan tandan sawit sebanyak $11.2 \%$, iaitu hampir dengan nilai PKB kaedah batas dalam kajian ini. Dalam kajian 
kebolehlaksanaan di Felda Sg. Behrang, penyelidikan tidak mengehadkan spesies pisang untuk biojisimnya diambil sebagai media. Ini kerana teknik yang dicadangkan oleh Jabatan Pertanian Filipina (2018) tidak menyatakan spesies pisang tertentu. Faktor kandungan nutrien substrat dan kebolehlekatan hifa pada substrat boleh mempengaruhi hasil kutipan (Sakinah et al. 2019). Berkemungkinan juga perlekatan hifa yang lebih kuat terbentuk apabila daun pisang yang disusun memanjang dalam kaedah batas membentuk siratan serat bersambung secara melintang berbanding kaedah bakul. Walau bagaimanapun, perkara ini masih memerlukan kajian lanjutan sebelum kesimpulan dapat dibuat.

Cendawan segar yang dihasilkan mendapat permintaan yang baik daripada pengguna dengan harga pasaran RM15.00/kg. Perbandingan anggaran kos dan hasil pulangan kasar antara media daun pisang dan tandan sawit ditunjukkan dalam Jadual 1. Kaedah tanaman menggunakan daun pisang kering memerlukan modal yang lebih rendah dan masa tuaian yang lebih pendek berbanding media tandan sawit (Jadual 1). Tempoh penanaman menggunakan media tandan sawit adalah 3 kali lebih panjang kerana tandan sawit perlu dikomposkan terlebih dahulu. Walau bagaimanapun, peratus pulangan modal bagi kaedah tanaman menggunakan daun pisang adalah $18 \%$ lebih rendah daripada media tandan sawit.

\section{ISU DAN CABARAN}

Dalam kajian ini, beberapa isu dan cabaran turut dihadapi. Pertamanya, tempoh penanaman selama 15 hingga 18 hari untuk kutipan pertama bagi media daun pisang adalah selari dengan keputusan oleh Della (2017). Della (2017) melaporkan bahawa selepas kutipan pertama batas media daun pisang perlu ditutup kembali dengan penutup plastik dan dibiarkan selama 7 hingga 14 hari lagi sebelum kutipan cendawan segar seterusnya. Walau bagaimanapun, dalam kajian ini, hanya kutipan pertama yang berjaya dilakukan. Didapati tiada lagi jasad cendawan berkembang selepas kutipan pertama walaupun batas ditutup kembali untuk tempoh inkubasi dan dipantau untuk kutipan seterusnya. Beberapa faktor boleh mempengaruhi hasil kajian ini seperti suhu, kelembapan udara dan pendedahan kepada oksigen dan karbon dioksida. Sepanjang uji kaji dari bulan April hingga Ogos 2018, data suhu yang direkodkan adalah dalam julat $28-34{ }^{\circ} \mathrm{C}$ dan kelembapan $55-75 \%$. Thakur dan Singh (2014) mencadangkan suhu 30-35 ${ }^{\circ} \mathrm{C}$ sebagai suhu yang optimum untuk penanaman $V$. volvacea dan suhu $32 \pm 2{ }^{\circ} \mathrm{C}$ untuk pembentukan jasad telur.
Pembentukan jasad telur juga memerlukan pengudaraan yang baik supaya peringkat butang mendapat oksigen dan karbon dioksida yang terperangkap semasa inkubasi terbebas keluar. Selain suhu, kelembapan relatif yang optimum untuk pertumbuhan $V$. volvacea adalah 70-90\% (Biswas \& Layak 2014). Jelas dalam kajian ini, tiadanya sebarang kawalan pada suhu, kelembapan dan pendedahan kepada karbon dioksida atau oksigen sepanjang uji kaji bagi kedua-dua kaedah telah mempengaruhi pertumbuhan dan kutipan hasil $V$. volvacea.

Selain itu, penggunaan media berasaskan sisa biojisim pisang untuk penanaman $V$. volvacea mempunyai kelebihan dan kekurangan. Sisa biojisim pisang boleh diperoleh dengan mudah dan banyak terutamanya daripada ladang pisang komersial. Kaedah penanaman secara terbuka juga berkos rendah kerana tidak memerlukan pembinaan rumah cendawan khas. Namun, penggunaan media tanaman yang lembap di atas tanah menarik serangan serangga perosak seperti semut yang boleh mengganggu pertumbuhan miselium semasa fasa pertumbuhan. Antara kerosakan yang berlaku akibat serangan serangga adalah perencatan pembentukan jasad telur dan kesan gigitan yang merendahkan kualiti cendawan (Kouakou et al. 2015).

Cabaran lain yang dihadapi adalah ketidakseragaman perkembangan fasa jasad cendawan pada media pertumbuhan. Misalnya, kewujudan peringkat cendawan matang dan peringkat jasad telur pada hari ke-17 hingga 18. Dari segi permintaan pengguna, peringkat jasad telur mendapat permintaan lebih tinggi. Sekiranya perkembangan fasa dapat diseragamkan, pengutipan hasil dapat dilakukan pada masa yang khusus untuk memenuhi permintaan pengguna.

\section{IMPLIKASI KAJIAN DAN CADANGAN}

Selain impak penjanaan sumber ekonomi baharu bagi tanaman komoditi sedia ada, manfaat alam sekitar utama projek ini ialah penjanaan sisa pertanian ladang pisang dapat diminimumkan dengan dikitar semula bagi penanaman cendawan $V$. volvacea bagi mencapai sasaran sisa sifar dan kitaran nutrien tertutup. Projek ini memberi implikasi kerangka model rujukan untuk diguna pakai sebagai amalan 'Home Grown Produce' dan ladang pisang lestari di kawasan lain di Perak dan Malaysia amnya dengan menggunakan kaedah permakultur yang organic serta kerangka model yang dicadangkan (Rajah 2). Dalam model ini, pokok pisang ditanam dalam barisan seperti amalan ladang konvensional. Pada sela jarak yang sesuai 
antara barisan pokok pisang, pokok moringa ditanam untuk menjalankan dua fungsi, iaitu pembekal nitrogen kepada akar pokok pisang dan pembekal daun moringa untuk penanaman cendawan jerami. Bagi memudahkan pengurusan dan automasi proses, cendawan jerami ditanam dalam rumah cendawan khas berteduh yang dibina di dalam ladang. Pengutipan daun pisang kering yang dilakukan secara berkala sebagaimana amalan ladang konvensional tidak lagi untuk dibakar tetapi dikumpulkan di rumah cendawan jerami bagi penghasilan media batas tanaman. Di dalam rumah cendawan, batas tanaman dicadangkan dibuat di rak untuk menyeragamkan perkembangan cendawan. Dalam kajian terkini di Indonesia, penggunaan rumah cendawan membolehkan kawalan suhu, limitasi udara, kelembapan dan perosak dilakukan (Triyono et al. 2019). Dengan memusatkan penanaman cendawan dalam rumah khas, tenaga buruh untuk penanaman dan pengutipan hasil dapat dijimatkan. Selepas kitaran penanaman cendawan berakhir, media sisa yang telah terkompos boleh dijadikan baja organik untuk dijual atau digunakan terus bagi menyuburkan tanah di ladang.

Oleh kerana hasil kajian yang diperoleh setakat ini masih pada peringkat awal dan lebih berfokuskan kebolehlaksanaan, beberapa cadangan kajian lanjutan turut disarankan seperti berikut: Pertama, kajian optimisasi pemboleh ubah seperti faktor pertumbuhan media yang merangkumi nutrisi media, komposisi media dan perbandingan hasil antara pertumbuhan secara terbuka dengan separa terkawal di rumah cendawan. Kedua, kajian pengurusan selepas tuai seperti kaedah penyimpanan, pengawetan dan pemprosesan produk hiliran. Cendawan V. volvacea tidak dapat bertahan lama dalam suhu bilik dan perlu dipasarkan secara segar sebaik sahaja dipetik dalam fasa telur dan matang. Dalam masa 4 hari, cendawan $V$. volvacea mengalami kehilangan $40-50 \%$ daripada berat jisimnya. Dalam kajian lepas, kesegaran cendawan jerami boleh dilanjutkan dengan pendedahan kepada karbon dioksida (Jamjumroon et al. 2012). Untuk pengusaha kecil, teknik lepas tuai yang berkos rendah adalah dijeruk dalam air garam dan dijual dalam tin (Sakinah et al. 2019). Sementara itu, pemprosesan produk hiliran yang sesuai diteroka adalah pembuatan burger vegetarian, sate, sos, nuget dan serbuk cendawan. Ketiga, kajian impak ekologi dan kitar ekonomi penanaman $V$. volvacea secara integrasi di ladang pisang komersial seperti yang dicadangkan dalam kerangka model pada Rajah 2. Selain cendawan segar, sumber ekonomi lain yang boleh dijana adalah penjualan bongkah cendawan dan penjualan baja organik daripada sisa media kompos selepas kitaran penanaman berakhir.

JADUAL 1. Perbandingan kaedah media daun pisang kering dan tandan sawit

\begin{tabular}{|c|c|c|}
\hline Perkara & $\begin{array}{c}\text { Media tandan sawit } \\
\text { (untuk } 20 \text { batas berukuran } 15 \times 3 \text { kaki } \\
\text { persegi) }\end{array}$ & $\begin{array}{c}\text { Media daun pisang } \\
\text { (untuk } 20 \text { batas berukuran } 5 \times 1 \times 1 \text { kaki padu) }\end{array}$ \\
\hline $\begin{array}{l}\text { Kos (termasuk modal } \\
\text { permulaan) }\end{array}$ & RM1000.00 & RM260.00 \\
\hline $\begin{array}{l}\text { Masa penanaman lengkap dari } \\
\text { penyediaan media hingga tamat } \\
\text { tuaian }\end{array}$ & 60 hari & 20 hari $/$ kitar $=3$ kali kitar untuk 60 hari \\
\hline $\begin{array}{l}\text { Hasil cendawan segar bagi } \\
\text { kitar tanaman } 60 \text { hari }\end{array}$ & $15 \mathrm{~kg} / \mathrm{batas} \times 20$ batas $=300 \mathrm{~kg}$ & $\begin{array}{c}2.5 \mathrm{~kg} / \mathrm{batas} \times 20 \text { batas } \times 3 \mathrm{kitar} \text { untuk } 60 \text { hari }= \\
150 \mathrm{~kg}\end{array}$ \\
\hline $\begin{array}{l}\text { Pendapatan kasar setiap kitar } \\
\text { tanaman } 60 \text { hari }\end{array}$ & $\mathrm{RM} 15.00 \times 300 \mathrm{~kg}=\mathrm{RM} 4500$ & $\mathrm{RM} 15.00 \times 150 \mathrm{~kg}=\mathrm{RM} 2250$ \\
\hline Untung kasar & $\mathrm{RM} 4500-1000=\mathrm{RM} 3500$ & $\begin{array}{c}*(\text { Modal } 3 \text { kitar RM260+160+160= RM580) } \\
\text { RM2250-580 }=\text { RM1670 }\end{array}$ \\
\hline
\end{tabular}




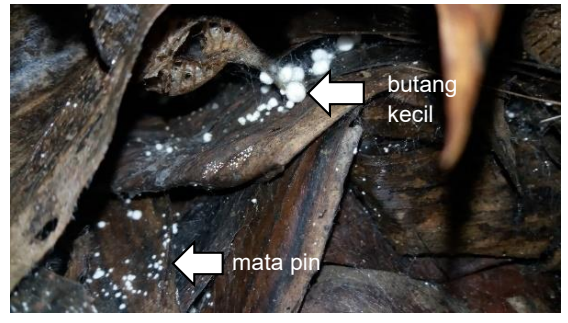

a) Hari ke-12

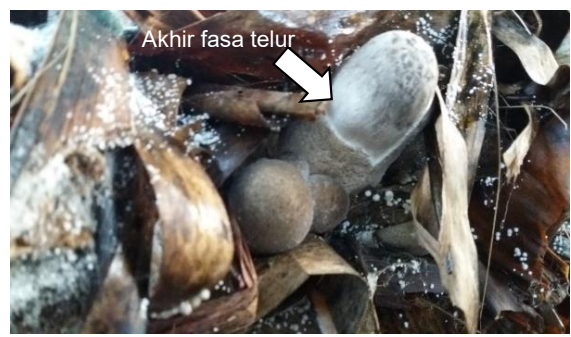

c) Hari ke-16

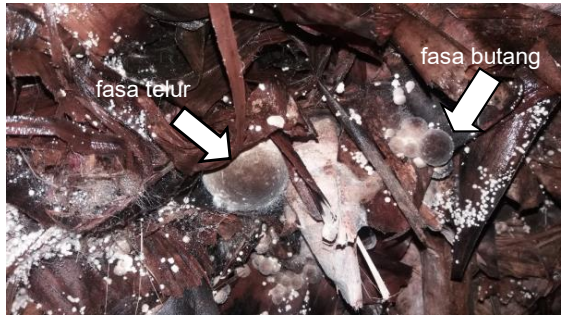

b) Hari ke-14 - 15

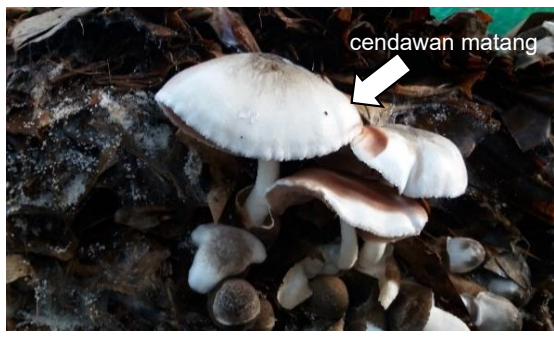

d) Hari ke-17 - 18

RAJAH 1. Fasa reproduktif $V$. volvacea di batas media daun pisang kering

(a) hari ke-12, (b) hari ke-14 - 15, (c) hari ke-16, dan (d) hari ke-17 - 18

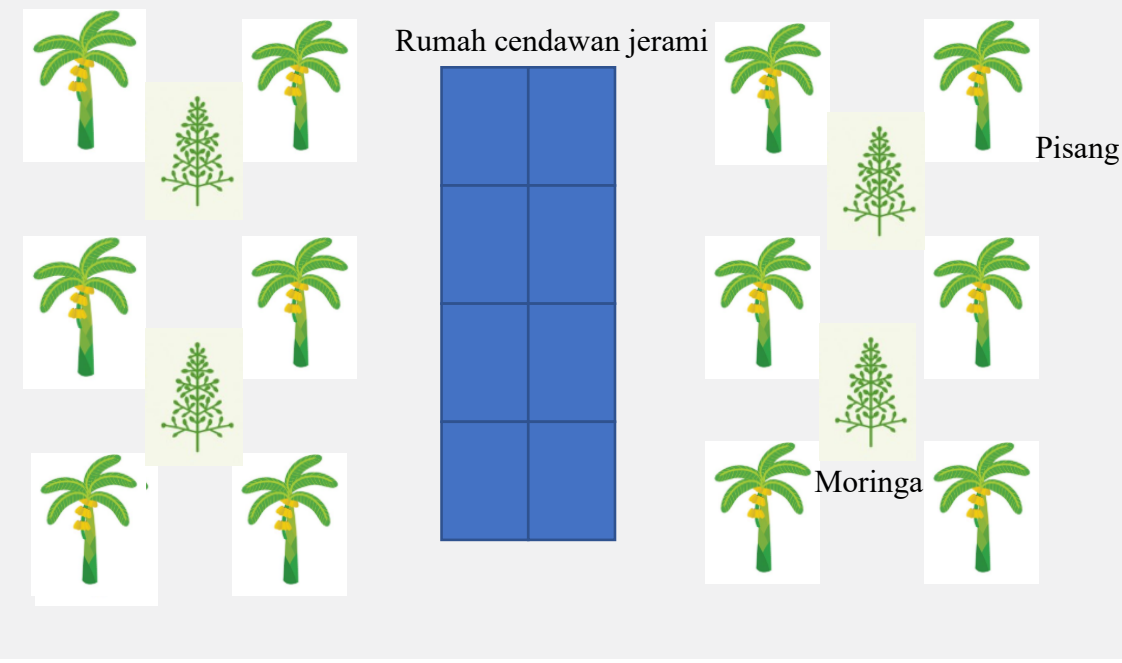

RAJAH 2. Model ladang lestari integrasi penanaman $V$. volvacea bersama pisang 


\section{KESIMPULAN}

Hasil kajian ini membuktikan penanaman $V$. volvacea boleh dilaksanakan menggunakan media sisa biojisim pisang terutama untuk penyediaan bongkah dan media pertumbuhan bagi pembentukan jasad cendawan. Kaedah batas didapati memberikan hasil yang signifikan lebih tinggi berbanding kaedah bakul. Walaupun penggunaan media sisa biojisim pisang memberikan pulangan pelaburan yang lebih rendah berbanding media tandan sawit, tempoh kitaran lengkap penanaman $V$. volvacea berjaya dipendekkan sebanyak separuh. Kajian ini memberikan data asas baharu yang secara langsung boleh dimanfaatkan oleh pengusaha tanaman cendawan dan agensi seperti Jabatan Pertanian, Agensi Nuklear Malaysia dan RISDA.

\section{PENGHARGAAN}

Penghargaan ditujukan kepada Universiti Pendidikan Sultan Idris yang telah membiayai penyelidikan ini melalui Geran Penyelidikan Institut Darul Ridzuan (Kod 2017-0099-102-01) dan kakitangan Makmal Pusat Pengeluaran dan Pembangunan Cendawan, Padang Nyior, Daerah Padang Terap, Kedah yang telah memberikan bantuan teknikal semasa kajian dijalankan.

\section{RUJUKAN}

Ahlawat, O.P. \& Tewari, R.P. 2007. Cultivation technology of paddy straw mushroom (Volvariella volvacea). Indian Council of Agricultural Research. National Research Centre for Mushroom (ICAR).

Amin, M.Z.M., Harun, A. \& Wahab, M.A.M.A. 2014. Status and potential of mushroom industry in Malaysia. Economic and Technology Management Review 9: 103-111.

Apetorgbor, A.K., Apetorgbor, M.M. \& Derkyi, N.S.A. 2015. Comparative studies on growth and yield of oil palm mushroom, Volvariella volvacea (Bull. Ex. Fr.) Sing. on different substrates. Greener Journal of Agricultural Sciences 5: $177-189$.

Biswas, M.K. \& Layak, M. 2014. Techniques for increasing the biological efficiency of paddy straw mushroom (Volvariella volvacea) in eastern India. Journal of Food Science and Technology 2: 52-57.

Comtrade. 2012. UN comtrade database. www. comtrade. un.org.

Della, C.G. 2017. PSU mushroom technology generation and research in Ilocos region. International Journal of Development Research 7: 13848-13856.

Eguchi, F., Kalaw, S.P., Dulay, R.M.R., Miyasa, N., Yoshimoto, H., Seyama, T. \& Reyes, R.G. 2015. Nutrient composition and functional activity of different stages in the fruiting body development of Philippine paddy straw mushroom, Volvariella volvacea (Bull.: Fr.) Sing. Advances in Environmental Biology 9: 54-65.
Haimid, M.T., Rahim, H. \& Dardak, R.A. 2013. Understanding the mushroom industry and its marketing strategies for fresh produce in Malaysia. Economic and Technology Management Review 8: 27-37.

Jamjumroon, S., Wongs-Aree, C., McGlasson, W.B., Srilaong, V., Chalermklin, P. \& Kanlayanarat, S. 2012. Extending the shelf-life of straw mushroom with high carbon dioxide treatment. Journal of Food Agriculture and Environment 10: 78-84.

Jabatan Pertanian Filipina. 2018. Straw Mushroom Production Guide. http://bpi.da.gov.ph.

Kementerian Pertanian dan Industri Asas Tani Malaysia. 2011. Dasar Agromakanan Negara (2011-2020). http:www/moa. gov.my.

Kouakou, T., Abou, B.K., Sery, E.G.B., Oula, N.A., Auguste, K., Philippe, K.K. \& Assanvo, S.N. 2015. Pests of mushrooms in Cote d'ivore: The case of Volvariella volvacea. International Journal of Agronomy and Agricultural Research 6: 251-255.

Le Vinh, T., Rizal, G.C., Julius, T.S., Ngo, T.T., Phan, H.H., Remelyn, E.R., Elmer, B. Caesar, J.M.T., Virgina, O., Dang, T.S. \& Nguyen, V.H. 2020. Rice-straw mushroom production. In Sustainable Rice Straw Management, edited by Gummert, M., Van Hung, N., Chivenge, P. \& Douthwaite, B. Berlin, Heidelberg: Springer International Publishing. pp. 93-109.

Maning Garden-Philippines. 2009. Maning GardenOrganic Straw Mushroom Culture. http://maninggardenorganicstrawmushroom.blogspot.my/.

Marshall, E. \& Nair, N.G. 2009. Make Money by Growing Mushrooms. Food and Agriculture Organization of the United Nations.

Rosmiza, M.Z., Davies, W.P., Rosniza Aznie, C.R., Jabil, M.J. \& Mazdi, M. 2016. Prospects of increasing commercial mushroom production in Malaysia: Challenges and opportunities. Mediterranean Journal of Social Sciences 7(1): 406-415.

Roy, A., Prasad, P. \& Gupta, N. 2014. Volvariella volvacea: A macrofungus having nutritional and health potential. Asian Journal of Pharmacy and Technology 4: 110-113.

Sakinah, N.M., Misran, A., Mahmud, T.M.M. \& Abdullah, S. 2019. A review: Production and postharvest management of Volvariella volvacea. International Food Research Journal 26: 367-376.

Sugalya, P., Pornsuda, C., Peerada, A., Malivan, H., Janpet, R., Wassana, T., Wassana, S. \& Chaisit, P. 2015. Cost and return of straw mushroom cultivation comparison between rice straw and oil palm bunch. Journal of Agricultural Technology 11: 2499-2504.

Thakur, M.P. \& Singh, H.K. 2014. Advances in the cultivation technology of tropical mushrooms in India. JNKVV Research Journal 48: 120-135.

Triyono, S., Haryanto, A., Telaumbanua, M., Dermiyati, Lumbanraja, J. \& To, F. 2019. Cultivation of straw mushroom (Volvariella volvacea) on oil palm empty fruit bunch growth medium. International Journal of Recycling of Organic Waste in Agriculture 8: 381-392. 
Yusof, S.C.M., Mohamad, A., Ismail, N., Haris, M.F., Haron, R., Zain, R.M. \& Nasir, M.H.A. 2019. Mushroom tea production training package in capacity building program to increase small medium industry (SME) entrepreneurs in rural area. International Journal of Entrepreneurship and Management Practices 2: 80-92.

Hanisom Abdullah*, Norlida Othman Marina Mokhtar \& Norjan Yusof

Jabatan Biologi, Fakulti Sains dan Matematik

Universiti Pendidikan Sultan Idris

35900 Tg. Malim, Perak Darul Ridzuan

Malaysia
Mohamad Yuzaidi Azmi

Jabatan Pertanian Negeri Kedah Telok Chengai

Jalan Kuala Kedah

06600 Kedah Darul Aman

Malaysia

Azhar Mohamad

Agensi Nuklear Malaysia, Bangi

43000 Kajang, Selangor Darul Ehsan

Malaysia

*Pengarang untuk surat-menyurat; email: hanisom@fsmt.upsi. edu.my

Diserahkan: 1 Januari 2020

Diterima: 6 November 2020 